\title{
Vascular Corrosion Casting
}

Fred E. Hossler

East Tennessee State University, J. H.Quillen College of Medicine, Department of Anatomy \& Cell Biology, Johnson City, TN 37614

With the development of low viscosity resins, casts of the fine capillary beds of tissues and organs were attainable, and these could be viewed and studied in detail in the scanning electron microscope [1, 2]. The advantage of such casts is that they permitted, for the first time, viewing of the, intact, threedimensional, complex vasculature of tissues and organs. It followed also that once vascular casts were obtained, quantitative measurements of various types could also be made from the casts if care was exercised. Of course, in theory, it should be possible to prepare casts of the three-dimensional lumenal space of any structure, biological or other [3]. However, this report will concentrate only on applications of corrosion casting to the vasculature of animal species.

Several modifications of the general method of preparing vascular corrosion casts are currently used in different laoratories, as well as several types of resins [4]. Outlined here is one method. After appropriate anesthetic and anticoagulant are administered (e.g. for rat, I use i.p injections of nembutal, $60 \mathrm{mg} / \mathrm{kg}$, and heparin, $700 \mathrm{U} / \mathrm{kg}$ ), an artery leading to the organ of interest is located and cannulated. The cannula is attached to one port on a three-way valve [5]. Another port on the valve is attached to a saline or Ringer reservoir (warmed to $37^{\circ} \mathrm{C}$ ), and the third port on the valve is attached to a syringe barrel. The entire system is joined to a manometer and pressure bulb for controlling perfusion pressure. A vein draining the organ of interest is opened as an outlet, and blood is flushed from the organ with the warm saline or Ringers solution at a pressure appropriate for the animal (80-100mm Hg for rats). Resin ( $8 \mathrm{ml}$ Mercox, $2 \mathrm{ml}$ methylmethacrylate monomer, and $0.3 \mathrm{ml}$ catalyst; prepared just before use) is placed in the syringe barrel and infused through the same cannula until the onset of polymerization (about 8-10 min). The perfused tissue is immersed in hot water for at least $1 \mathrm{hr}$ to complete polymerization, the tissue is removed with alternating treatments of $5 \% \mathrm{KOH}$ and distilled water, and the resulting cast is cleaned with formic acid and distilled water. The cast is dried by lyophilization, mounted on a stub, and sputter coated for routine SEM observation.

Example corrosion casts from various tissues including heart [6], lung [7], urinary bladder [8], and salt gland [9] will be shown. Some of the types of anatomical information that can be obtained from casts, such as the presence of valves, sphincters, and nuclear imprints, as well as some examples of simple quantitative measurements, will be presented. 


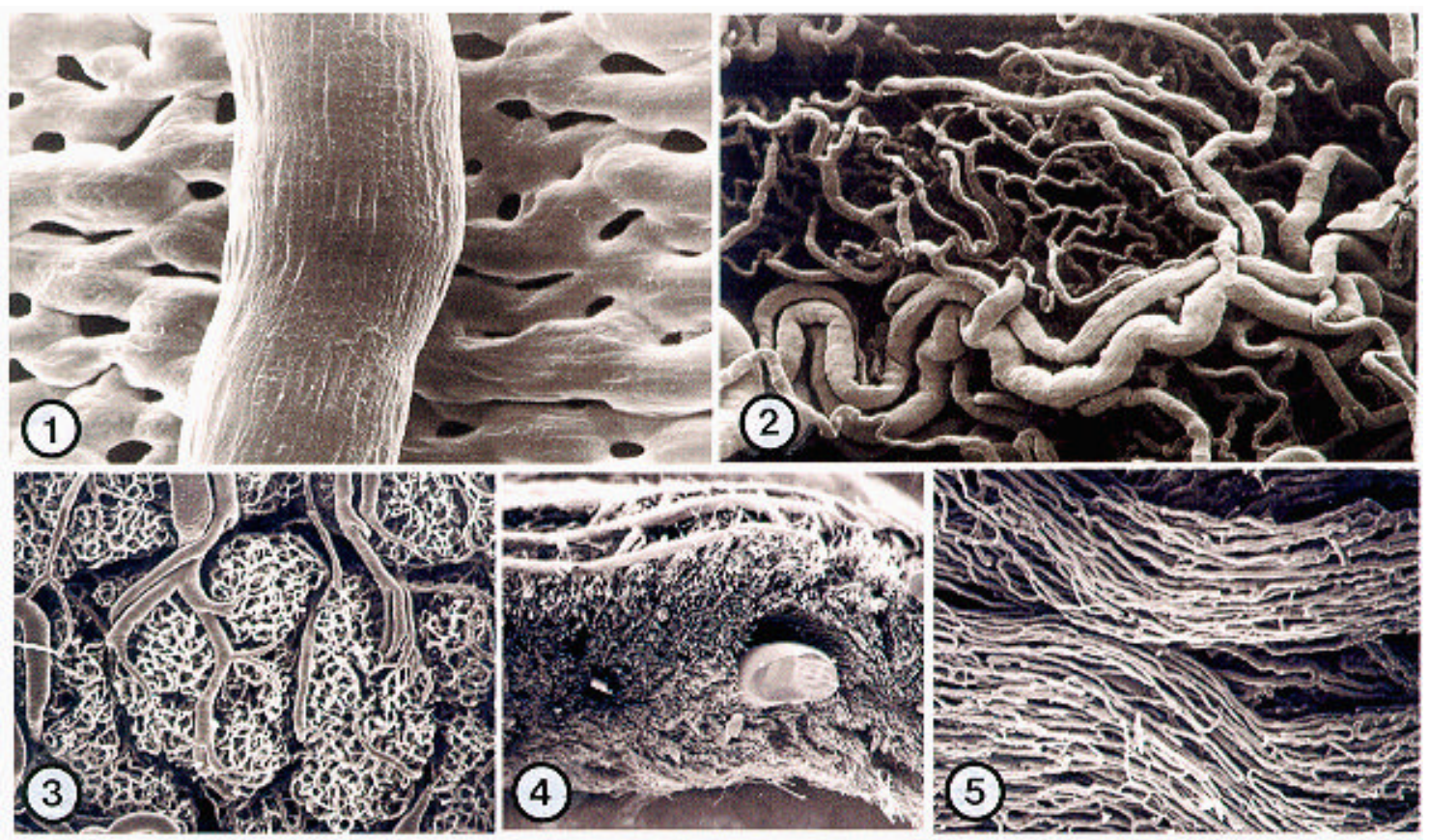

Fig. 1. Vascular corrosion cast of frog retina, showing endothelial imprints (arrowheads) in an artery (A) and in capillaries (C). x200

Fig. 2. Vascular corrosion cast of the submucosal vasculature of the rabbit bladder. A, artery; V, vein; arrowhead, sphincter at an arterial branch point. x86

Fig. 3. Vascular corrosion cast of the avian salt gland. A, artery; V, vein; C, capillary bed. x70

Fig. 4. Vascular corrosion cast of the right ventricular free wall of a rat heart. Epicardium, E; endocardium, EN. x22

Fig. 5. Vascular corrosion cast of capillary beds of the trabecular muscle in rat heart. $\mathrm{x} 120$

\section{References}

[1] T. Murakami, Arch. Histol. Jpn. 32 (1971) 445.

[2] J.A. Nowell, et al., Scanning Electr. Microsc. 1970 (1970) 249.

[3] F. E. Hossler, Microsc. Today 98-7 (1998) 14.

[4] A. Lametschwandtner, et al., Scanning Microsc, 4 (1990) 889.

[5] K. R. Olson, J. Electron Microsc. Tech. 2 (1985) 217.

[6] F. E. Hossler, et al., Scanning Electron Microsc, 1986/IV (1986) 1469.

[7] F. E. Hossler, et al., J. Electron Microsc. Tech. 19 (1991) 406.

[8] F. E. Hossler and F.C. Monson, Anat. Rec. 243 (1995) 438.

[9] F. E. Hossler and K. R. Olson, J. Exp. Zool. 254 (1990) 237. 